\title{
Changes in the Number of Newly Diagnosed Lung Cancer Patients Before and During the COVID-19 Pandemic: A single-Center Experience
}

\section{Sule Gul ( $\sim$ suleeyhan@gmail.com )}

University of Health Sciences, Yedikule Chest Diseases and Chest Surgery Education and Research Hospital https://orcid.org/0000-0002-7162-2611

\section{Mehmet Atilla Uysal}

University of Health Sciences, Yedikule Chest Diseases and Chest Surgery Education and Research Hospital

\section{Atilla Çifter}

Altınbaş University: Altinbas Universitesi

\section{Elif Yelda Özgün Niksarlığlu}

University of Health Sciences, Yedikule Chest Diseases and Chest Surgery Education and Research Hospital

\section{Deniz Bilici}

Medeniyet University Goztepe Training and Research Hospital: Medeniyet Universitesi Goztepe Egitim ve Arastirma Hastanesi

\section{Research Article}

Keywords: COVID-19, hospital admission, lung cancer

Posted Date: December 20th, 2021

DOI: https://doi.org/10.21203/rs.3.rs-1178735/v1

License: (c) (i) This work is licensed under a Creative Commons Attribution 4.0 International License. Read Full License 


\section{Abstract}

This study was conducted to determine whether there was an effect on the hospital admissions of newly diagnosed lung cancer (NDLC) patients in Turkey during the COVID-19 pandemic. In this retrospective study, NDLC patients were recorded from the Hospital Information Management System between January, 1 2015-December, 31, 2020, at our tertiary hospital. The number of NDLC patients diagnosed in 2020 was compared with each year of 2017-2019. Between 2017 and 2020, 15,150 NDLC cases were analyzed. The number of NDLC patients by year were; 4,030 patients in $2017,4,004$ patients in 2018 , 4,391 patients in 2019 , and 2,725 in 2020 , respectively. In 2020 , NDLC patients decreased by $38 \%, 32 \%$, $32 \%$ compared to 2019,2018 , and 2017 , respectively. The late admission of lung cancer patients might result in the advanced stage, missing the chance for surgery, and decreased survival. Precautions should be considered to diagnose and treat lung cancer patients in specialized centers during a pandemic due to epidemic diseases such as COVID-19.

\section{Introduction}

The COVID-19 pandemic has become a significant health crisis affecting the world after its first appearance in Wuhan, China. According to the data of WHO, on April 26, 2021, 146,881,882 cases were detected worldwide, causing 3,104,743 deaths [1]. Since March 11, 2020, when the first case was seen in our country, 4,667,281 cases, and 38,711 deaths were reached, according to the data of the Ministry of Health on April 26, 2021 [2]. After the date of the first case, restrictions have been implemented, and stayat-home orders took place on March 20, and continued until May 11, 2020. With the end of lockdown and releasing restrictions, an increase in COVID-19 cases was observed. Stay-at-home recommendations were begun on November 17, 2020. With the lockdown and restrictions again, the number of COVID-19 cases has tended to decrease. During all these stay-at-home recommendations and lockdown periods, the health system was also affected, and there were problems in patients' access to the health system.

According to the Global Cancer Observatory (GCO), 2020 data, lung cancer is the 2nd most common cancer type globally and the most common cause of death [3]. In Turkey, 41,264 (17.6\%) lung cancer cases were seen in 2020, and lung cancer was the most common type of cancer. It ranked first in cancerrelated deaths with a rate of $29.3 \%$ [4]. Several studies show that the survival and cure rates increase with a lung cancer diagnosis at an early stage. ${ }^{5}$ During the COVID-19 pandemic, the number of hospital admissions, screening, and diagnostic tests, and access to treatment of lung cancer patients are affected $[5,6]$.

We aimed to evaluate the changes in the number of newly diagnosed lung cancer (NDLC) patients during the COVID-19 pandemic in a big hospital for chest diseases and thoracic surgery.

\section{Material And Methods}


The patients who applied to Health Sciences University xxxx hospital, Turkey, were evaluated between January 1, 2015, and December 31, 2020. The recorded patients were recruited from our Hospital Information Management System according to their first admission dates. Patients diagnosed with definite lung cancer among these patients were extracted according to the ICD-10 codes (C34, C34.0, C34.1, C34.2, C34.3, C34.8, C34.9). Lung cancer patients between 2015 and 2016 were excluded from the analysis to avoid recurrent cancer diagnosis, yet, the NDLC patients between 2017 and 2020 were included in the study. In the statistical data of the Public Health Cancer Department, the latest lung cancer data in our country belonged to 2016. Cancer data of our country are also available in the Global Cancer Observatory (GCO) system of the World Health Organization in 2018 and 2020. GCO uses the data of Ankara, Antalya, Bursa, Edirne, Erzurum, Eskişehir, İzmir, Samsun and Trabzon Cancer Registries for incidence estimates for Turkey. Cancer data of our country is given by the ratio of the population of the regions represented by the centers and Turkey's population data. With the GCO 2018 and 2020 lung cancer data, the rate of NDLC patients in our hospital according to country data was determined as point prevalence. The number of NDLC patients in 2020 was compared with the number of NDLC patients in 2017, 2018, and 2019. Between 2017 and 2020, NDLC cases were converted into monthly time series according to their admission dates.

\section{Statistics}

For continuous data, percentages, mean, and standard deviation(SD) values were used. Mann Whitney U test was used according to the normality assumption for continuous variables, Pearson Chi-square and Fisher's Exact Test were used for categorical variables. $\mathrm{P}<0.05$ was considered as statistically significant. There is seasonal variation in hospital admission in NDLC cases, and seasonal adjustment was applied using the X-13ARIMA-SEATS method via WinRATS (2021) software. A structural break in seasonally adjusted monthly lung cancer admissions was investigated by Bai and Perron structural break test $[7,8]$. This test can detect the time and statistical significance of structural breaks in time series data.

\section{Results}

The number of NDLC cases admitted to our hospital between January 1, 2015, and December 31, 2020, were 7,245 in 2015, 4,500 in 2016, 4,030 in 2017, 4,004 in 2018, 4,391 in 2019, and 2,725 in 2020, respectively. A total of 26.895 cases were extracted from the database to evaluate the lung cancer patients. In 2018, 34,703 NDLC cases were observed in Turkey, according to GCO data. In the same year, 4,004 patients were diagnosed in our hospital. Thus, for $2018,11.54 \%$ of the cases in Turkey were diagnosed in our hospital. In 2020, according to GCO data, 41,264 NDLC cases were detected in our country. In our hospital, 2,725 lung cancer patients were diagnosed. Therefore, by $2020,6.6 \%$ of all cases in Turkey were diagnosed in our hospital.

The demographic data of the patients admitted between 2017 and 2020 and the ratio of all cases admitted to the hospital were given in Table 1. There were no significant changes in the mean age of the patients by years $(p>0.05, p>0.05, p>0.05, p>0.05$, respectively). The ratio of male patients compared to 
females was higher for all years. Although there was no decrease in the total number of hospital admission in 2020 , compared to previous years, the number of NDLC patients decreased by $38 \%, 32 \%$, $32 \%$ compared to 2019,2018 , and 2017 years $(p=0.000, p=0.001$, and $p=0.002$ respectively) (Figure 1 ). The number of admissions by months of NDLC cases were shown in Figure 2. There was a significant decrease in the number of NDLC cases in March 2020, when there were stay-at-home restrictions. The number of lung cancer cases increased in the subsequent months by releasing restrictions. However, the number of NDLC patients decreased again in October-November 2020, when the restrictions were applied due to the increase in COVID-19 cases.

Table 1

Demographic characteristics of newly diagnosed lung cancer cases by year and the ratio to the total number of cases admitted to the hospital.

\begin{tabular}{|lllll|}
\hline & 2017 & 2018 & 2019 & 2020 \\
\hline Age (Mean \pm STD) & $62.69 \pm 10.62$ & $62.25 \pm 10.75$ & $\begin{array}{l}62.42 \pm \\
11.04\end{array}$ & $\begin{array}{l}61.67 \pm \\
11.43\end{array}$ \\
\hline Male n(\%) & $3,242(80.44)$ & $3,178(79.37)$ & $\begin{array}{l}3,421 \\
(77.90)\end{array}$ & $\begin{array}{l}2,189 \\
(80.31)\end{array}$ \\
\hline Female (\%) & $788(19.56)$ & $826(20.63)$ & $970(22.10)$ & $536(19.69)$ \\
\hline $\begin{array}{l}\text { Newly diagnosed lung cancer cases } \\
(\mathrm{n})\end{array}$ & 4030 & 4004 & 4391 & 2725 \\
\hline $\begin{array}{l}\text { Total number of hospital admissions } \\
(\mathrm{n})\end{array}$ & 185647 & 221589 & 234289 & 208003 \\
\hline Ratio (\%) & 2.17 & 1.81 & 1.87 & 1.31 \\
\hline
\end{tabular}

The mean number of NDLC cases per month were 335.8 \pm 50.9 (min-max: 273-434) in 2017, 333.6 \pm 31.3 (min-max: 272-383) in 2018, 365.9 \pm 39.2 STD (min-max: 299-432) in 2019, and 227 \pm 88.5 (min-max: 96394 ) in 2020, respectively. The number of NDLC cases was seasonally dependent, and we firstly adjusted the cases using the X-13ARIMA-SEATS method. Figure 2 shows the raw and seasonally adjusted number of newly diagnosed lung cancer data. This figure indicates that lung cancer cases should be seasonally adjusted since variations between the raw and adjusted observations. Secondly, we use Bai and Perron test to figure out if there is a statistically significant structural break in 2020. Table 2 shows the structural break date in March 2020 with a 5\% significance level. Turkey announced its first Covid-19 patient on March 11, 2020, and this structural break date shows fear of coronavirus and its impact on hospital admission for lung cancer. Figure 3 shows the structural break period with a graph. 
Table 2

Bai and Perron structural break test

\begin{tabular}{|lll|}
\hline Break Test & F-statistic & Critical value \\
\hline 0 vs. 1 & $93.91 *$ & 8.58 \\
\hline 1 vs. 2 & 6.41 & 10.13 \\
\hline Break Date & $2020 \mathrm{M} 03$ \\
\hline * Significant at the 0.05 level. \\
\hline
\end{tabular}

\section{Discussion}

Our study showed a significant decrease in NDLC cases in 2020 compared to the previous three years, especially during the COVID-19 pandemic onset and stay-at-home restriction period.

Early diagnosis of lung cancer and an early stage are factors that increase survival by increasing the chance of surgery. While the 5 -year survival rate is $50 \%$ in Stage $1 \mathrm{~A}$ lung cancer, this rate drops to $2 \%$ in Stage 4 [9]. Only less than $20 \%$ of patients present at the operable stages [5]. There are patient or systemrelated reasons for patients' late admission to the hospital. Patient-related causes include age, gender, socioeconomic status, employment status, and awareness of smoking. Patients with chronic illnesses might apply late due to their chronic symptoms or health condition. The reasons originating from the physicians or the health system might be summarized as follows: examination by a physician from other than chest diseases, misinterpretation of radiology, focusing on different diagnoses, not getting an appointment due to systemic problems, or late diagnostic procedures [10].

Epidemics such as COVID-19 affect the entire health system, affecting patients' hospital admission and receiving adequate health care. Several studies show a decrease in the number of cranial imaging performed to detect stroke or hospitalization due to acute myocardial infarction during the COVID-19 pandemic $[11,12]$. Cancer patients may also be affected by this situation, and diagnosis may be delayed due to late hospital admission. It has been shown that there is a $25 \%$ reduction in cancer cases in the March-May 2020 pandemic period in the Netherlands [13]. In Spain, between March and June 2020, the number of new cancer cases decreased by $20.8 \%$ compared to 2019 , the number of biopsies performed for diagnosis was lower, and the number of visits for patients receiving cancer treatment decreased [14]. In a study from the USA, the number of cases of six cancer types, including lung cancer, decreased significantly in March and April compared to the first two months of 2020 [15]. In our study, there was a significant decrease in hospital admissions in NDLC cases, especially during the lockdown periods of the pandemic. According to GCO 2020, the total number of lung cancer cases detected in Turkey was not lower than in 2018. However, the number of NDLC cases diagnosed in our hospital in 2020 was lower than in previous years. This difference might be due to the GCO registry system using other nine cities' hospital data of the country except our tertiary chest diseases hospital. The other factors contributing to the low number of NDLC cases may be as follows; caring for active COVID -19 patients in our hospital, 
can not performing interventional procedures in the first period of the pandemic, and then performing less in number than previous years during the entire pandemic period.

A published meta-analysis observed that a 12-week delay in surgery in lung cancer patients significantly reduced survival [16]. In Park et al.'s study, during the COVID-19 pandemic in Korea, NSCLC patients applied at a more advanced stage than in previous years [6]. Although the stages of the patients and the treatments they received could not be documented in our study, the decrease in the admissions of NDLC patients, especially during the restriction periods of the pandemic, may cause to apply in the advanced stages and reduce the survival. A modeling study from England showed that there might be a 4.8-5.3\% higher mortality within five years in lung cancer patients due to delayed diagnosis in the COVID-19 period [17].

It should also be kept in mind that lung cancer patients have a higher risk of contracting COVID-19, and mortality may be higher due to infection. It has been reported that $76 \%$ of patients with thoracic malignancies infected with COVID-19 required hospitalization and a mortality rate of $33 \%$ [18]. Since there is no significant difference between the survival of lung cancer patients infected with COVID-19 and the survival of advanced lung cancer due to late presentation, even in lung cancer patients who are candidates for surgery, if the perioperative risk of COVID-19 is greater than $13 \%$, the operation may be delayed. Still, immediate surgery increases survival if there is a low risk of COVID-19 [19]. For this reason, it is crucial to arrange centers where the diagnosis and treatment of lung cancer patients can be carried out, even during the most intense periods of restrictions during the pandemic period. Considering that epidemic diseases such as COVID-19 can exist in any period, necessary precautions should be taken beforehand.

There are some limitations of our study. Firstly, it is a study that includes only one center from Turkey. Secondly, the pathological diagnoses, stages, and treatments of the patients could not be documented. For this reason, although it was shown that there was a decrease in the number of admissions, patients' cancer stages and whether the cancer treatment was affected could not be demonstrated. Third, we do not know whether the patients were infected with COVID-19 and caused late admission.

\section{Conclusion}

In our center, lung cancer patient admissions statistically decreased during the COVID-19 pandemic period. Early diagnosis and treatment are essential in lung cancer, one of the leading causes of death. During the pandemic period, failure of patients to be diagnosed on time may cause patients to apply at an advanced stage and decrease survival. It is crucial to allocate suitable and separate hospitals where patients can use and maintain diagnosis and treatment for lung cancer and other malignancies during the pandemic period.

\section{Declarations}


Funding interest: The authors did not receive support from any organization for the submitted work

Conflict of interest: The authors have no competing interests to declare that are relevant to the content of this article.

Ethics Declaration: This study was performed in line with the principles of the Declaration of Helsinki. Approval was granted by the University of Health Sciences Hamidiye Scientific Ethics Committee (18.6. 2021-21/4).

Author contribution: Conceptualization: Sule Gul, Mehmet Atilla Uysal, Elif Yelda Özgün Niksarlıoğlu, Methodology: Sule Gul, Mehmet Atilla Uysal, Investigation: Sule Gul, Deniz Bilici, Data Curation: Sule Gul, Mehmet Atilla Uysal, Elif Yelda Özgün Niksarlıoğlu, Writing - Original Draft: Sule Gul, Mehmet Atilla Uysal, Atilla Çifter, Elif Yelda Özgün Niksarlıŏlu, Writing - Review \& Editing: Sule Gul, Mehmet Atilla Uysal, Elif Yelda Özgün Niksarlıoğlu, Methodology and Software: Sule Gul, Mehmet Atilla Uysal, Atilla Çifter, Formal analysis, Resources: Sule Gul, Mehmet Atilla Uysal, Atilla Çifter,

\section{References}

1. WHO Coronavirus (COVID-19) Dashboard I WHO Coronavirus (COVID-19) Dashboard With Vaccination Data. https://covid19.who.int/. Accessed 27 Apr 2021.

2. Covid19. https://covid19.saglik.gov.tr/. Accessed 27 Apr 2021.

3. WHO. (2020) World fact sheets cancers. Globocan 2020 419:1-2.

4. (2020) The Global Cancer Observatory, Turkey Registry. https://gco.iarc.fr/today/data/factsheets/populations/792-turkey-fact-sheets.pdf.

5. Patt D, Gordan L, Diaz M, et al (2020) Impact of COVID-19 on Cancer Care: How the Pandemic Is Delaying Cancer Diagnosis and Treatment for American Seniors. JCO Clinical Cancer Informatics 1059-71. https://doi.org/10.1200/cci.20.00134.

6. Park JY, Lee YJ, Kim T, et al. Collateral effects of the coronavirus disease 2019 pandemic on lung cancer diagnosis in Korea. BMC Cancer. 2020;20:1-8. https://doi.org/10.1186/s12885-020-07544-3.

7. Bai J, Perron P. Estimating and Testing Linear Models with Multiple Structural Changes.

Econometrica. 1998;66:47. https://doi.org/10.2307/2998540.

8. Bai J, Perron P. Computation and analysis of multiple structural change models. J Appl Econom. 2003;18:1-22. https://doi.org/10.1002/jae.659.

9. Goldstraw P, Crowley J, Chansky K, et al. The IASLC lung cancer staging project: Proposals for the revision of the TNM stage groupings in the forthcoming (seventh) edition of the TNM classification of malignant tumours. Journal of Thoracic Oncology. 2007;2:706-14. https://doi.org/10.1097/JT0.0b013e31812f3c1a.

10. Yurdakul AS, Kocatürk $\mathrm{C}$, Bayiz $\mathrm{H}$, et al. Patient and physician delay in the diagnosis and treatment of non-small cell lung cancer in Turkey. Cancer Epidemiol. 2015;39:216-21. https://doi.org/10.1016/j.canep.2014.12.015. 
11. Solomon MD, McNulty EJ, Rana JS, et al. The Covid-19 Pandemic and the Incidence of Acute Myocardial Infarction. N Engl J Med. 2020;383:691-3. https://doi.org/10.1056/nejmc2015630.

12. Kansagra AP, Goyal MS, Hamilton S, Albers GW. Collateral Effect of Covid-19 on Stroke Evaluation in the United States. N Engl J Med. 2020;383:400-1. https://doi.org/10.1056/nejmc2014816.

13. Dinmohamed AG, Visser O, Verhoeven RHA, et al. Fewer cancer diagnoses during the COVID-19 epidemic in the Netherlands. The Lancet Oncology. 2020;21:750-1.

14. Amador M, Matias-Guiu X, Sancho-Pardo G, et al. Impact of the COVID-19 pandemic on the care of cancer patients in Spain. ESMO Open. 2021;6:100157. https://doi.org/10.1016/j.esmoop.2021.100157.

15. Kaufman HW, Chen Z, Niles J, Fesko Y. Changes in the Number of US Patients With Newly Identified Cancer Before and During the Coronavirus Disease 2019 (COVID-19) Pandemic. JAMA network open. 2020;3:e2017267. https://doi.org/10.1001/jamanetworkopen.2020.17267.

16. Brett A, Johnson, Anthony C, Waddimba GOO, James W. Fleshman Jr JTP (2020) A systematic review and meta-analysis of surgery delays and survival in breast, lung and colon cancers: Implication for surgical triage during the COVID-19 pandemic.

17. Maringe C, Spicer J, Morris M, et al. The impact of the COVID-19 pandemic on cancer deaths due to delays in diagnosis in England, UK: a national, population-based, modelling study. The Lancet Oncology. 2020;21:1023-34. https://doi.org/10.1016/S1470-2045(20)30388-0.

18. Van Haren RM, Delman AM, Turner KM, et al. Impact of the COVID-19 Pandemic on Lung Cancer Screening Program and Subsequent Lung Cancer. J Am Coll Surg. 2021;232:600-5. https://doi.org/10.1016/j.jamcollsurg.2020.12.002.

19. Shipe ME, Haddad DN, Deppen SA, et al (2020) Modeling the Impact of Delaying the Diagnosis of Non-Small Cell Lung Cancer During COVID-19. The Annals of Thoracic Surgery. https://doi.org/10.1016/j.athoracsur.2020.08.025.

\section{Figures}


200000

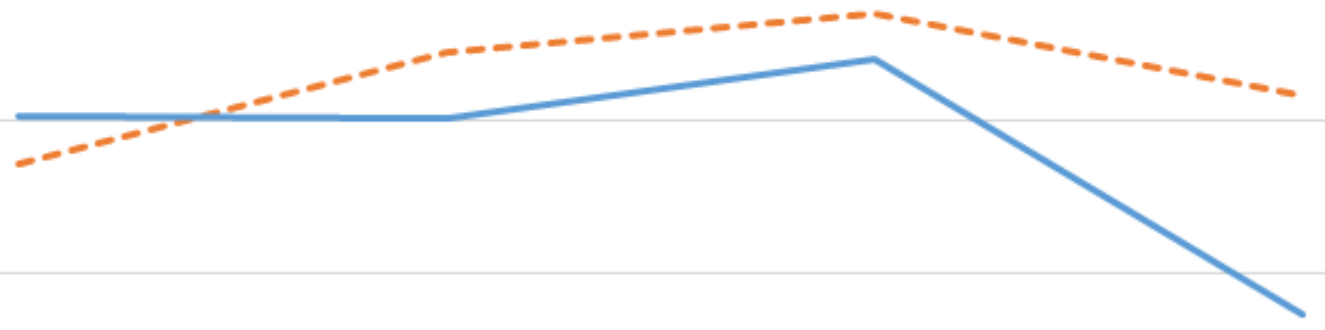

150000

Figure 1

Number of all cases and newly diagnosed lung cancer cases between 2017 and 2020

500

450

400

350

300

250

200

150

100

50

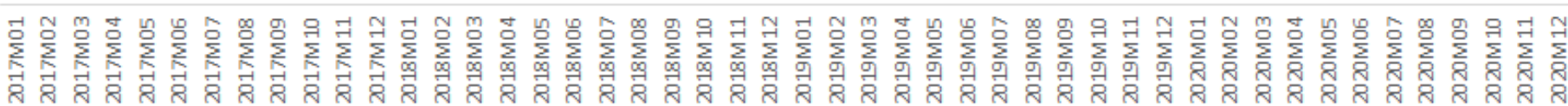

Newly diagnosed lung cancer cases with X-13ARIMA-SEATS 
Figure 2

Number of newly diagnosed lung cancer cases and seasonally adjusted data

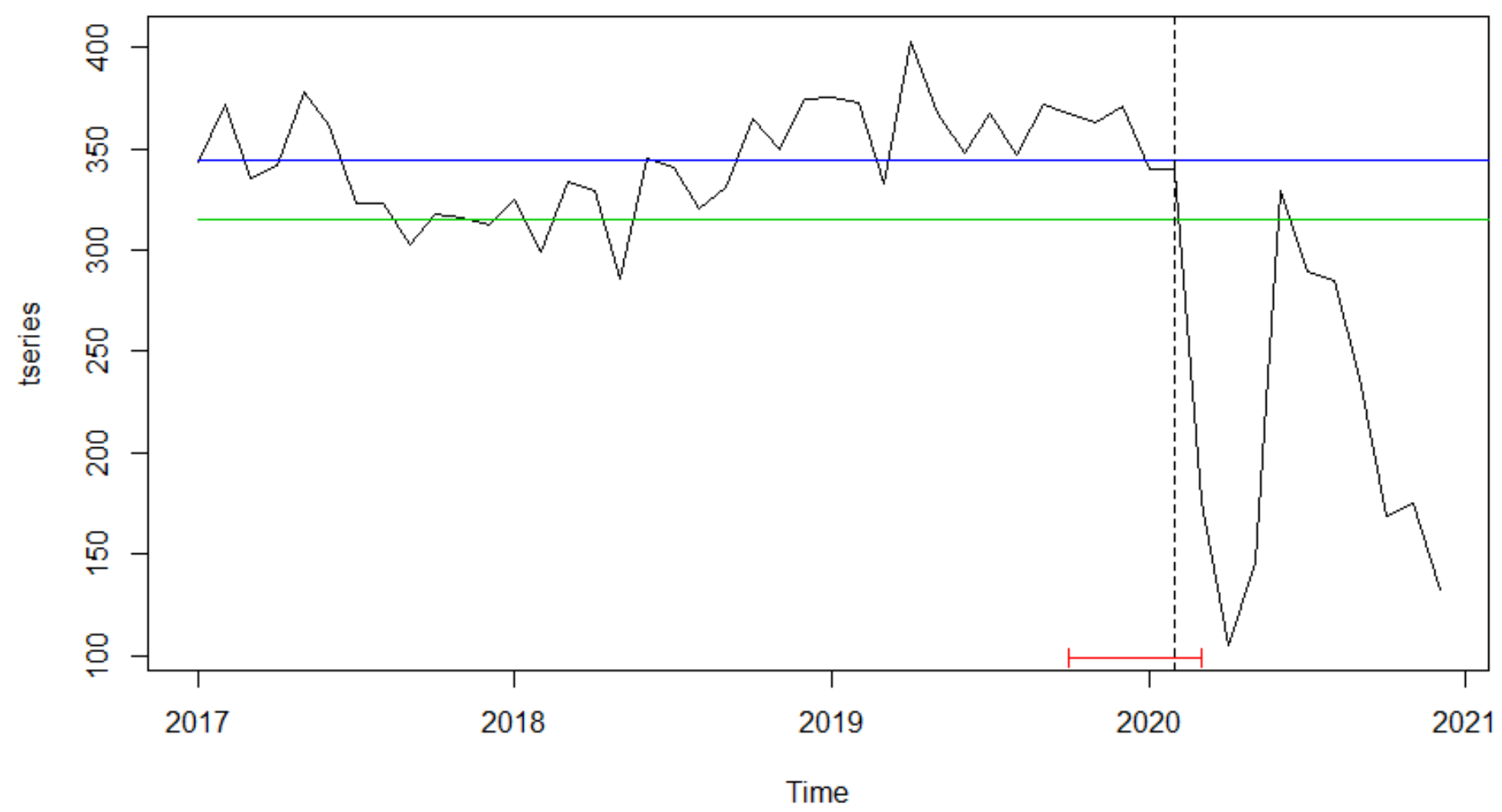

Figure 3

The structural break period with a graph 